\title{
APPLICATION OF BENFORD'S LAW FOR FRAUD DETECTION IN FINANCIAL STATEMENTS: THEORETICAL REVIEW
}

\author{
Mihkel Tammaru \\ Tallinn University of Technology, Estonia \\ Lehte Alver \\ Tallinn University of Technology, Estonia
}

\begin{abstract}
External auditors' ability to detect profit manipulations in the financial statements is limited. Non conformity with Benford's law gives indication of the risk that a data set contains fraud, but it does not give information which items are manipulated. Knowing profit and other financial targets set to the companies it is possible, treating profits deviation from Benford's law as probability, to identify potential financial statements with manipulated profits. In this field there has been a lot of research in different countries (New Zealand, USA, Finland, Japan, Germany and the others). The above-mentioned probability describing the profit manipulation risk would be very useful information for interested parties to decide whether identified financial statements require additional inspection. The aim of the current paper is to characterize Benford's law as tool for detecting financial statements with manipulated profits. The paper gives some ideas how to combine Benford's law and analytical tests.
\end{abstract}

Keywords: financial statements, Benford's law, profit manipulation

JEL: M410, M420

\section{Introduction: Characteristics of Benford's law}

Benford's Law defines the frequency distribution of digits in a data set from the first position to the fourth position (starting from the left). According to Newcomb (1881) and Benford (1938), the frequency distribution of digits zero to nine, also known as the distribution of digits, follows a logarithmic frequency distribution which depends on the position of the digit. Table 1 shows the Benford's distribution for the first four digits. From the fourth position onwards, the Benford's distribution approaches a uniform distribution Newcomb (1881). A data set which corresponds to Benford's law is generally referred to as a Benford's set.

Table 1. Expected frequencies based on Benford's law

\begin{tabular}{|c|c|c|c|c|}
\hline Digit & $1^{\text {st }}$ place & $2^{\text {nd }}$ place & $3^{\text {rd }}$ place & $4^{\text {th }}$ place \\
\hline 0 & - & .11968 & .10178 & .10018 \\
\hline 1 & .30103 & .11389 & .10138 & .10014 \\
\hline 2 & .17609 & .19882 & .10097 & .10010 \\
\hline 3 & .12494 & .10433 & .10057 & .10006 \\
\hline 4 & .09691 & .10031 & .10018 & .10002 \\
\hline 5 & .07918 & .09668 & .09979 & .09998 \\
\hline 6 & .06695 & .09337 & .09940 & .09994 \\
\hline 7 & .05799 & .09035 & .09902 & .09990 \\
\hline 8 & .05115 & .08757 & .09864 & .09986 \\
\hline 9 & .04576 & .08500 & .09827 & .09982 \\
\hline
\end{tabular}

Source: Nigrini, 1996

Not every large, un-manipulated data set automatically follows Benford's law. In any case, a close conformity to Benford's law can generally be expected, if the following conditions are met (Nigrini 2000): 
1. All data must be recorded in the same unit. This implies that all data must describe the same phenomenon.

2. The data set may not contain any inherent minimums or maximums. In particular, this means that there may be no limits that determine whether a data point is or is not included in the investigated data set. For example, a data set may not contain only invoices in excess of EUR 50, because smaller invoices are not issued.

3. The data set may not include any assigned numbers. Assigned numbers have the purpose of identification and do not therefore arise from any natural calculation process. Thus ID codes, bank accounts and telephone numbers do not conform to the Benford's distribution.

4. A data set should tend to have more small than large numbers, which also accords with the natural development process. For example, it can be expected in general, that small invoices are found more often than large ones. Nonetheless, the data set does not have to be dispersed widely (Raimi 1976).

Benford's set has the following characteristics:

1. Scale invariance: multiplying all values in the Benford's Set by any constant creates also Benford's Set, as described by Pinkham (1961). This Benford's law property is particularly relevant with respect to change of unit of measurement.

2. Base invariance: Hill (1995) was able to provide evidence that Benford's Law applies not only to numerical systems with a basis of 10 , but in all other numerical systems as well.

3. Sum invariance: Nigrini (1992) remarked that in tables of data distributed according to Benford's law, the sum of all elements with the first digit or digits are approximately constant.

Benford's law has several properties that would make it potentially a very useful tool for assessing the risk whether the profit in the company's financial statements have been manipulated.

\section{Application of Benford's law for profit manipulation detection}

In the field of Benford's law there has been a lot of research recently. Carslaw (1998) has applied Benford's law in the research of New Zealand companies to determine whether the management is rounding up companies' profits or not. His results showed that 0 as the second digit was overused and 9 as the second digit was underused. He concluded that for financial statements users the profit of 50 million makes a better impression than the profit of 49 million and therefore the management rounds up the profit figures. A company's profit rounding has been studied also by Thomas (1989) based on US companies, Niskanen and Keloharjo (2000) based on Finnish companies, Van Caneghem (2002) based on UK companies, Kinnunen and Koskela (2003) based on companies of 18 countries, Skousen (2004) based on Japanese companies. South Korean companies' profits have also been studied using Benford's law Guo (1995). German companies' 5-year financial statements have been studied by Quick and Wolz (2005). The above mentioned research papers do not group companies based on the financial targets' first digit or digits and do not deal with the identification of potentially manipulated financial statements and financial statements items. Therefore, theoretical and experimental research is needed in this field, considering how useful such probability based knowledge about profit manipulations risk would be for the capital providers, external auditors and other interested parties. External auditors' ability to detect financial profit manipulations is limited. There have been several accounting scandals in the past related with large public companies audited by large audit firms. 


\section{Application of Benford's law in auditing}

Benford's law defines probabilities of digits on the first four positions in number. It is similar to the conception of quantitative audit materiality. Quantitative audit materiality is the threshold above which incorrect information in financial statement items is considered to have an impact on the decision making by users. Methods and ranges of audit materiality vary in different audit firms and audit assignments. For example, based on the audit risk, the auditor will select a value inside this range:

- $0.5 \%$ to $1 \%$ of gross revenue;

- $1 \%$ to $2 \%$ of total assets;

- $1 \%$ to $2 \%$ of gross profit;

- $2 \%$ to $5 \%$ of shareholders' equity;

- $5 \%$ to $10 \%$ of net profit.

If a company's profit is EUR 2,345,567 and an auditor applies 5\% materiality based on the net profit, the cumulative misstatement impact on the net profit is +/-EUR 117,278 without qualifying the auditor's report. A profit in the range of EUR 2,228,289 to EUR 2,462,285 is acceptable. Rounding these figures to the nearest 100,000, the company's profit varies in the range of EUR 2,200,000 to EUR 2,500,000 and there is no impact on decision making by the users of financial statements. The profit targets are also set up using approximated figures. For example, in the above discussed case the profit target was EUR 2,100,000. It is important to emphasize for the evaluation of the company's profit that the relevant information is based on the first two or three digits.

\section{Calculating Benford's law based probabilities and identifying potentially manipulated financial statements and financial statement items}

After receiving relevant data for testing and maintaining the required minimum sample size, it is possible to calculate probabilities that a company's profit and other financial statement items are manipulated (see Formula 1).

$$
p=\frac{A-B}{N}
$$

$\mathrm{p}$ - probability that a financial statement item is manipulated to fulfil the profit target;

B - expected amounts of items according to Benford's law;

A - actual amounts of items;

$\mathrm{N}$ - actual amounts of potential financial statements with manipulated profits (financial statements where the profit target was barely achieved);

$\mathrm{A}-\mathrm{B}>0$.

As it was mentioned above for profit manipulation it is necessary to manipulate at least one of the additional items the in balance sheet and income statement. If the potential financial statements with manipulated profits are known the auditors can perform analytical procedures. This helps to find out which items in the balance sheet and income statement were used in profit manipulation.

\section{Conclusion and Future Research}

For the further research, application of Benford's law makes it very useful for detecting profit manipulations. After reading special scientific literature the authors of the current paper have the opinion that there is a possibility of calculating the probability of manipulation with a profit if the company has set up for the management to achieve the targeted profit. The first digits of the profit follow the Benford's distribution. The significant over usage of the first 
digits of the targeted profit suggests that manipulation has occurred. The potentially manipulated financial statements can be tested through analytical tests. At the same time, it is possible to clarify which financial statement items were used in the process of manipulation.

Benford's law has the following qualities that would make it potentially a very useful tool for detecting profit manipulations:

- similarity with the quantitative audit materiality;

- un-manipulated profits in financial statements follow Benford's law.

For the research purposes it is necessary to collect initial data. Annual financial statements especially in the conditions of electronic reporting systems are available for the public. Information about companies' profit targets is not publicly available, therefore necessary information for research is missing but there are some potential alternatives:

- In some countries profit budgets are part of annual financial reporting of public sector entities.

- To receive information from banks. They have useful information and they must be interested that their customers will not manipulate with profits to fulfil loan covenants. But for researchers this is still confidential information.

- It would be possible to ask companies to provide information about their profit targets voluntarily.

Although this study cannot claim to be exhaustive, the authors believe that it will provide new information for anyone interested in assessing the risk of profit manipulation in financial statements using Benford's law.

\section{Literature}

Benford, F (1938). The law of anomalous numbers. Proceedings of the American Philosophical Society, vol. 78, no. 4, pp. 551-572.

Carslaw, C. (1988). Anomalies in income numbers: evidence of goal oriented behavior. The Accounting Review, vol. 63, no. 2, pp. 321-327.

Guo, M. (1995). Patterns in reported earnings in Korea. Journal of International Accounting, Auditing and Taxation, 4 (1), pp. 39-47.

Hill, T. P. (1995). Base-Invariance Implies Benford's Law. Proceedings of the American Mathematical Society, vol. 123, no. 3, pp. 887-895.

Kinnunen, J., Koskela M. (2003). Who Is Miss World in Cosmetic Earnings Management? A Cross-National Comparison of Small Upward Rounding of Net Income Numbers among Eighteen Countries. Journal of International Accounting Research, no. 2, pp. 39-68.

Niskanen, J., Keloharjo M. (2000). Earnings cosmetics in a tax-driven accounting environment: evidence from Finnish public firms. European Accounting Review vol. 9, no. 3, pp. 443-452.

Newcomb, S. (1881). Note on the frequency of use of the different digits in natural numbers. American Journal of Mathematics, Vol. 4 no. 1, pp. 39-40.

Nigrini, M. J. (1996) A taxpayer compliance application of Benford's law. Journal of the American Taxation Association, vol. 18, no. 1, pp. 72-91.

Nigirini M. J. (2000). Digital Analysis Using Benford's Law tests \& statistics for auditors. Global Audit Publications. 
Pinkham, R. S. (1961). On the Distribution of First Significant Digits. Annals of Mathematical Statistics 32 (4), pp. 1223-1230.

Raimi, R. A. (1976). The First Digit Problem. American Mathematical Monthly vol. 83, no. 7, pp. 521-538.

Skousen C. J, Guan L., Wetzel T. S. (2004). Anomalies and unusual patterns in reported earnings: Japanese managers round earnings. International Financial Management Accounting, vol. 15, no. 3, pp. 212-234.

Thomas, J. (1989). Unusual patterns in reported earnings. The Accounting Review, vol. 64, no. 4, 773-787.

Van Caneghem T. (2002). Earnings Management induced by Cognitive reference points. The British Accounting Review, vol. 34, pp. 167-178. 